Int. J. Electrochem. Sci., 12 (2017) 7890 - 7910

\title{
Carbon Supported Mono- and Bi-Metallic Dispersed Thin Film Catalysts for Oxygen Electro-Reduction Reaction in Acid Medium
}

\author{
M.A. Abdel Rahim, M.W. Khalil and M.A. Sultan ${ }^{*}$ \\ Department of Chemistry, Faculty of Science, University of Cairo, Giza, 12613, Egypt \\ "E-mail: $\underline{\text { m_a_sultan2006@yahoo.com }}$
}

doi: $10.20964 / 2017.08 .23$

Received: 18 December 2016 / Accepted: 26 May 2017 / Published: 12 July 2017

\begin{abstract}
The present study reports the use of mono- and binary-metal thin film deposits of $\mathrm{Pt}, \mathrm{Cu}, \mathrm{Ru}$ and $\mathrm{Pd}$ dispersed over carbon electrode as electro-catalysts for oxygen reduction. The metals are sequentially electrodeposited on the carbon electrode from their aqueous solutions using the potentiostatic technique. The electrode surface characterization was carried out by scanning electron microscopy (SEM), X-ray diffraction (XRD) and energy dispersed X-ray (EDX). The micrographs of SEM analyses showed that the thin films of the various deposits are located at the electrode surface in the nano-scale range. Linear sweep voltammetry was used to investigate the electrode performance towards oxygen reduction in $\mathrm{H}_{2} \mathrm{SO}_{4}$ solution in the absence and presence of $\mathrm{H}_{2} \mathrm{O}_{2}$. The results indicated that metal deposits and platinum-metal modified carbon electrodes have shown superior electro-catalytic activity toward oxygen reduction reaction (ORR) as shown by the relative increase in the peak current density values of oxygen reduction.
\end{abstract}

Keywords: Oxygen reduction, Dispersed electrodes, $\mathrm{Pt}, \mathrm{Pt}-\mathrm{Cu}, \mathrm{Pt}-\mathrm{Pd}$.

\section{FULL TEXT}

(C) 2017 The Authors. Published by ESG (www.electrochemsci.org). This article is an open access article distributed under the terms and conditions of the Creative Commons Attribution license (http://creativecommons.org/licenses/by/4.0/). 